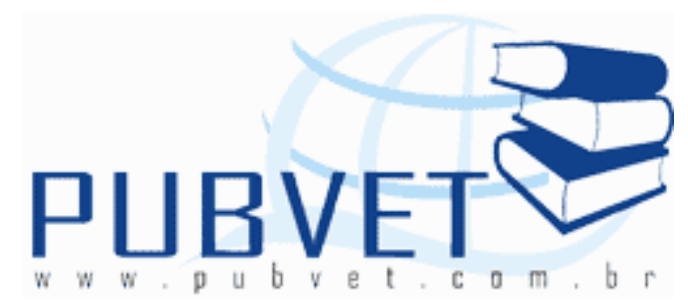

PUBVET, Publicações em Medicina Veterinária e Zootecnia.

\title{
Ciclos estrais de curta duração em vacas no pós-parto
}

Jose Eduardo Jardim Murta ${ }^{1}$, Venício Jose de Andrade $^{2}$

1 Professor de Educação Superior (Departamento de Ciências Agrárias, UNIMONTES), doutorando em Zootecnia (Escola de Veterinária, UFMG), bolsista da FAPEMIG.

2 Professor Titular, Departamento de Zootecnia, Escola de Veterinária, UFMG, Brasil. E-mail: jardimmurta@hotmail.com

\section{Resumo}

O objetivo desta revisão foi demonstrar as razões para ocorrência de ciclos estrais de curta duração, após indução hormonal do estro em vacas de corte e leiteiras em anestro pós-parto. Conclui-se que a ocorrência de ciclos estrais de curta duração pode ser decorrente de desenvolvimento inadequado do folículo ovulatório, suporte gonadotrófico inadequado, falha do corpo lúteo na resposta a gonadotrofinas, estímulo luteolítico precoce e sensibilidade do corpo lúteo aos luteolíticos.

Palavras-chave: Ciclo estral, corpo lúteo, bovino. 


\title{
Oestral cycles of short duration in post partum cows
}

\begin{abstract}
The purpose of this review was to demonstrate the reasons for the occurrence of estrous cycles of short duration after hormonal induction of estrus in beef cows and dairy postpartum anestrus. It is concluded that the occurrence of short estrous cycles may be due to inadequate development of the ovulatory follicle, gonadotropin inadequate support, failure of the corpus luteum in response to gonadotrophin stimulation and early luteolytic sensitivity of the corpus luteum to the luteolytic.
\end{abstract}

Keywords: Cycle oestral, ovulation, pregnancy, bovine.

\section{Introdução}

O anestro pós-parto é um período de transição durante o qual a funcionalidade do eixo hipotalâmico-hipofisário-ovariano-uterino se recupera da gestação anterior. As primeiras três semanas pós-parto têm grande importância para involução uterina, reposição dos estoques hipofisários do Hormônio Luteinizante (LH) e início do crescimento de ondas foliculares (YAVAS \& WALTON, 2000).

Portanto, o prolongamento do período de anestro pós-parto é fator determinante para baixos índices reprodutivos, sendo fonte de perdas econômicas na produção de bovinos. Dentre as diferentes causas, a subnutrição e o anestro lactacional têm sido considerados os principais responsáveis pela longa duração do anestro e da baixa eficiência reprodutiva pós-parto (SHORT et al., 1990).

O objetivo deste trabalho é demonstrar as razões para ocorrência de ciclos estrais de curta duração, após indução hormonal do estro em vacas de corte e leiteiras em anestro pós-parto. 
MURTA, J.E.J. e ANDRADE, V.J. Ciclos estrais de curta duração em vacas no pós-parto.

PUBVET, Londrina, V. 6, N. 33, Ed. 220, Art. 1465, 2012.

\section{Revisão de literatura}

A ocorrência de fase lútea curta após primeira ovulação ou primeiro estro foi inicialmente notificada por Menge et al. em 1962 e Morrow et al. em 1966. Em 1985, reuniram-se dados que permitiram extensas revisões por Lauderdale (1986) e por Garverick \& Smith (1986). Posteriormente, uma serie de estudos foram realizados onde variáveis como desenvolvimento folicular, concentrações de gonadotrofinas pré e pós ovulação e receptores luteais para LH mostraram ser responsáveis pelas variações na função luteal (revisão de LISHMAN \& INSKEEP, 1991), mas não para sua duração. Então, Copelin et al (1989), Peters et al (1989) e Coopers et al (1991) mostraram claramente que a secreção uterina prematura de PGF2a foi responsável pela fase lutea de curta duração (INSKEEP, 1995).

Vários autores, entre eles Ramirez-Godinez et al (1981), observaram que o pré tratamento com progestágeno resulta na formação de corpo lúteo com vida útil normal após desmama ou aplicação de gonadotrofinas. Deduziu-se então que o útero quando não exposto a progestágeno eleva a secreção de PGF2a prematuramente em resposta ao baixo nível de secreção de progesterona pelo primeiro corpo lúteo (INSKEEP, 1995).

Após o parto, a primeira ovulação resulta na formação de um corpo lúteo $(\mathrm{CL})$ de curta duração e também um menor ciclo estral de reduzida fertilidade. Estruturas luteais similares a este $\mathrm{CL}$ são formadas em decorrência de tratamentos com o uso de GnRH ou hCG e em resposta aos sistemas de desmame precoce e interrompido. Possivelmente, a progesterona produzida por esse corpo lúteo e o estrógeno formado pelo folículo tenham importante função na duração do ciclo estral e na fertilidade inicial (CORAH et al, 1974). O útero no pós-parto pode produzir maiores quantidades de PGF2a, e quando ocorre a primeira ovulação essa maior concentração de PGF2a lisa o corpo lúteo assim que este se torna responsivo, resultando numa fase lutea curta (RIVERA et al., 1998). 
MURTA, J.E.J. e ANDRADE, V.J. Ciclos estrais de curta duração em vacas no pós-parto.

PUBVET, Londrina, V. 6, N. 33, Ed. 220, Art. 1465, 2012.

A primeira ovulação pós parto geralmente ocorre sem estro (ovulação silenciosa) e é acompanhada por um ciclo estral curto ( 8 a 12 dias) na maioria das vacas. O ciclo estral curto é também comum após a ovulação induzida pela desmama, desmama associada ao $\mathrm{GnRH}$, única aplicação de $\mathrm{GnRH}$, aplicação intermitente de $\mathrm{GnRH}$, aplicação contínua de $\mathrm{GnRH}$, única aplicação de hCG e após a primeira ovulação na puberdade (YAVAS e WALTON, 2000).

O ciclo curto é decorrente de onda folicular simples, menor corpo lúteo que o do ciclo normal e concentrações sub luteais de progesterona circulante (YAVAS e WALTON, 2000). A taxa de concepção (76 e 41\%) após inseminação artificial ao primeiro estro pós parto foi maior $(p<0,01)$ nas vacas que apresentaram elevação na concentração de progesterona após o primeiro estro que naquelas não apresentando elevação na Progesterona. Os resultados indicam que se houver pré exposição à Progesterona os resultados na taxa de concepção são melhores (WERTH et al., 1996).

Considera-se luteólise precoce a regressão do corpo lúteo antes do $16^{\circ}$ dia do ciclo estral, ou seja, antes que o endométrio inicie, fisiologicamente, a secreção pulsátil de PGF2a em ciclo estral de duração normal.

Diferentes hipóteses têm sido postuladas sobre ciclos curtos, como desenvolvimento inadequado do folículo ovulatório, suporte gonadotrófico inadequado, falha do $\mathrm{CL}$ na resposta a gonadotrofinas, estímulo luteolítico precoce e sensibilidade do CL aos luteolíticos (YAVAS e WALTON, 2000).

Estudos sugerem que a menor vida útil do $\mathrm{CL}$ decorrente da primeira ovulação pós parto, pode ser devido à luteólise precoce envolvendo o útero. Experimento objetivando determinar o efeito do útero na vida útil luteal e o padrão de secreção de progesterona após o desmame precoce em vacas de corte, foi desenvolvido por Copelin et al. (1987). Os autores compararam a duração do ciclo estral em dois grupos: controle e histerectomizado. O grupo controle apresentou o primeiro ciclo estral $(8,8 \pm 0,3$ dias) mais curto ( $p \square 0,01)$ 
MURTA, J.E.J. e ANDRADE, V.J. Ciclos estrais de curta duração em vacas no pós-parto.

PUBVET, Londrina, V. 6, N. 33, Ed. 220, Art. 1465, 2012.

que o segundo ciclo estral (20,2 $\pm 0,5$ dias), indicando que a exposição prévia à Progesterona é fator determinante na vida útil do $\mathrm{CL}$ subseqüente. Os autores sugerem que no dia 6 após o primeiro estro, o útero apresenta um efeito luteolítico em vacas que tiveram seus bezerros desmamados precocemente.

Baseado nos dados descritos anteriormente supõe-se que a luteólise prematura seja resultado da ovulação sem prévia exposição à Progesterona. Utilizando dispositivos intra vaginais de Progesterona por sete dias, associado ou não ao desmame temporário de bezerros, para indução de ciclicidade em vacas em anestro, Vasconcelos e colaboradores (2009) desenvolveram experimento. Os autores observaram maior taxa de prenhez após a primeira inseminação artificial no tratamento combinando Progesterona com desmame temporário. Provavelmente a pré exposição à Progesterona tenha reduzido a ocorrência de ciclos estrais de curta duração, neste experimento.

Tem sido postulado também que a luteólise prematura é decorrente de baixos níveis circulantes de Estradiol pré ovulatório, devido à menor secreção de Estradiol por folículos que originam $\mathrm{CL}$ de regressão precoce. O pré tratamento com progestágeno para evitar ciclo estral de curta duração no pós parto resulta em maior concentração circulante de Estradiol (GARVERICK et al., 1988). Parece que a exposição previa ao progestágeno exerce efeito direto, prevenindo a secreção prematura de Prostaglandina e efeito indireto, pela maior secreção de Estradiol pelos folículos.

Animais que são induzidos a ovular folículos pequenos no tratamento com GnRH podem apresentar ciclos estrais de menor duração. A antecipação na aplicação da segunda dose do GnRH no protocolo Ovsynch, reduziu as taxas de concepção, provavelmente devido a ocorrência de ciclos de curta duração, uma vez que este índice foi similar em animais tratados com protocolo convencional (PETERS e PURSLEY, 2003).

Conclui-se que a maturação do folículo dominante parece ser influenciada por eventos diversos, entre eles destacam-se o controle endócrino 
MURTA, J.E.J. e ANDRADE, V.J. Ciclos estrais de curta duração em vacas no pós-parto.

PUBVET, Londrina, V. 6, N. 33, Ed. 220, Art. 1465, 2012.

exercido pelo eixo hipotálamo-hipofise-gonadal, além da relação com os hormônios metabólicos e substratos nutricionais.

A ocorrência de ciclos estrais de curta duração não está bem esclarecida, podendo ser decorrente de desenvolvimento inadequado do folículo ovulatório, suporte gonadotrófico inadequado, falha do corpo lúteo na resposta a gonadotrofinas, estímulo luteolítico precoce e sensibilidade do corpo lúteo aos luteolíticos.

\section{Referências bibliográficas}

COPELIN, J. P., SMITH, M. F., GARVERICK, H. A., and YOUNGQUIST, R. S. Effect of the uterus on subnormal luteal function in anestrous beef cows. Journal of Animal Science, v. 64, p. 1236-1245, 1987

INSKEEP, E. K. Factors that affect fertility during oestrous cycles with short or normal luteal phases in postpartum cows. Journal of Reproduction and Fertility. Suplement 49, p. 493-503, 1995

GARVERICK, H. A., PARFET, J. R., LEE, C. N., COPELIN, J. P., YOUNGQUIST, R. S. and SMITH, M. F.. Relationship of pre- and post-ovulatory gonadotropin concentrations to subnormal luteal function in postpartum beef cattle. Journal of Animal Science, v. 66, p. 104-111, 1988

RIVERA, G. M. et al. Ovarian follicular wave synchronization and induction of ovulation in postpartum beef cows. Theriogenology, v. 49, p. 1365-1375, 1998

PETERS, M. W. and PURSLEY, J. R. Timing of final GnRH of the Ovsynch protocol affects ovulatory follicles size, subsequent luteal function, and fertility in dairy cows. Theriogenology. V. 60(6), p. $1197-1204,2003$

SHORT, R. E., BELLOWS, R.A., STAIGMILLER, R.B., BERARDINELLI, J.G., CUSTER, E.E. Physiological mechanisms controlling anestrous and infertility in post partum beef cattle. Journal Animal Science, v.68, p.799-816, 1990.

VASCONCElos, J. L. M., SÁ FILHO, O. G., PEREZ, G. C., SILVA, A. T. N. Intravaginal progesterone device and/or temporary weaning on reproductive performance of anestrous crossbred Angus $\times$ Nelore cows. Animal Reproduction Science, v. 111, p. 302-311, 2009

YAVAS, Y., WALTON, J. S. POSTPARTUM ACYCLICITY IN SUCKLED BEEF COWS: A REVIEW. THERIOGENOLOGY, N. 54, P. 25-55, 2000

WERTH, L. A., WHITTIER, J. C., AZZAM, S. M., DEUTSCHER, G. H. and KINDER, J. E. Relationship between circulating progesterone and conception at the first postpartum estrus in young primiparous beef cows. Journal of Animal Science, v. 74, p. 616-619, 1996 